\title{
DOSSIÊ
}

\section{Maristela Salvatori}

\section{Expressões do múltiplo: práticas interdisciplinares}

\section{Resumo}

0 presente texto traz aspectos de pesquisas desenvolvidas recentemente no universo do múltiplo, em suas diferentes expressões na contemporaneidade, tomando por base projetos vinculados ao Grupo de Pesquisa Expressões do Múltiplo (CNPq-PPGAV/IA/UFRGS).

\section{Palavras-chave}

Múltiplo. Gravura. Arte contemporânea. Fotografia. 
1. Grupo que criei em 2009 em parceria com Maria Lucia Cattani (UFRGS). Vinculado à linha de pesquisa Desdobramentos da Imagem do Programa de PósGraduação em Artes Visuais do Instituto de Artes da UFRGS, 0 grupo, atualmente, conta com a coliderança de Helena Kanaan (UFRGS).

2. Com foco na arte impressa, o projeto The Power of Printmaking objetiva incentivar, difundir e integrar as manifestações de artistas contemporâneos no âmbito da gravura e suas extensões. Mais adiante, serão abordadas algumas das realizações vinculadas.
Longe de dias onde a previsão pessimista de alguns, e desdém de outros, preconizava o irreversível declínio de toda prática artística que pressupunha alguma atividade manual, hoje observamos campos abertos a inúmeras e diferentes formas e concepções de arte. Sendo recorrente o uso simultâneo de recursos tecnológicos mais avançados e de tecnologias arcaicas, também é frequente a permeabilidade das fronteiras - ocorrendo a expansão dos meios e contaminação com diferentes linguagens.

Conforme Maria do Carmo de Freitas Veneroso: "A troca frequente que tem existido entre as linguagens artísticas faz com que, ao interagirem umas com as outras, elas contribuam para que ocorra uma ruptura com antigos parâmetros que preservavam a autonomia das disciplinas (2014, p.172)." No campo específico da gravura, a autora aponta que: "A apropriação de imagens pré-existentes, a colagem, os processos fotográficos" e "a busca da tridimensionalidade na gravura são alguns dos fatores que colaboram" para sua expansão (Op. cit., p.175). Para Paul Coldwell, na cena contemporânea, gravura é uma arte multifacetada, com processos sobrepostos, na qual novos processos surgem e velhas tecnologias são revisitadas (2010, p.33).

No contexto local e institucional, o Instituto de Artes da UFRGS tem promovido eventos que reafirmam estas premissas. Por meio do Grupo de Pesquisa Expressões do Múltiplo (CNPq-PPGAV/IA/UFRGS) ${ }^{1}$ temos nos dedicado, nos últimos anos, a pesquisas em torno do múltiplo e, notadamente, sobre gravura, em campo ampliado, realizando estudos, experimentações e proposições poéticas. Neste sentido, destacaremos aqui algumas ações e projetos tais como The Rape of Europe e Rhinos are coming, concretizados em parceria com a Faculdade de Belas-Artes da Universidade de Lisboa, o projeto Rhinoceros, realizado em parceria com o Goethe-Institut Porto Alegre, que por sua vez está promovendo o projeto The Power of Printmaking ${ }^{2}$, também com parcial contribuição do IA/UFRGS, ou ainda a promoção de seminários e de exposições, como a panorâmica sobre a obra de Maria Lucia Cattani, a exposição sobre obras de Nilza Haertel e, a coletiva, Expressões do Múltiplo.

Estas atividades tem engajado grandes equipes compostas de estudantes, teóricos e artistas pesquisadores vinculados ao IA/UFRGS e atingido um público numeroso. 
Este universo de produtores e este público ávido não cessam de crescer e encontrar espaço em eventos sem qualquer vinculação, mas que se somam aos esforços acadêmicos, como a Parada Gráfica, promovida pelo Museu do TrabaIho, e feiras que, regularmente, ou eventualmente, são promovidas pelo Santander Cultural, entre outras instituições.

\section{UMA PARCERIA ALÉM MAR}

Os projetos The Rape of Europe e Rhinos are coming, que localmente tiveram a minha curadoria, foram realizados em parceria com a Faculdade de Belas-Artes da Universidade de Lisboa (FBAUL). Tiveram como foco a produção e intercâmbio de gravuras e modelos semelhantes, contaram com a participação de artistas vinculados a instituições de ensino superior de arte e culminaram em exposições e em seminários, em 2013 e 2014.

The Rape of Europe, buscou trazer e ressignificar os encantos e dramas do mito de criação do continente europeu e engajou estudantes e professores da FBAUL, instituição propositora, da Faculty of Visual Arts and Design at the HKU, de Uthrecht, Holanda, da Facultat de Belles Arts de la Universitat de Barcelona, Espanha, da Akademia Sztuk Pieknych, de Lodz, Polônia, e do Instituto de Artes da Universidade Federal do Rio Grande do Sul (IA/UFRGS). Em cada instituição, um artista curador convidou um outro professor e oito estudantes para o desafio de realizar obras de gravura e/ou instalações gráficas a partir do mito.

Para o projeto, foram concebidas gravuras, monotipias, objetos e instalações, bastante diversas, que constituíram um rico panorama da produção vinculada às escolas participantes. O conjunto foi, em Porto Alegre, exibido na Sala Fahrion, da Reitoria da UFRGS. Tratando-se de obras múltiplas, exposições semelhantes foram apresentadas simultaneamente nas demais cidades sede das instituições envolvidas ${ }^{3}$.

Concomitantemente às exposições, em Lisboa e em Porto Alegre, foram realizados seminários homônimos sobre o mito de Europa com pesquisadores das instituições participantes.

No ano seguinte, repetiu-se a parceria com a FBAUL, novamente no campo ampliado da gravura, no projeto Rhinos are coming, que buscava antecipar-se às comemorações previstas para 2015, dos 500 anos de Ganda, o emblemático rinoceronte eternizado por Dürer.

Nesta edição, como na anterior, os artistas curadores, todos vinculados a instituições de ensino superior de arte, convidaram um outro colega e oito estudantes para participar. Além do IA/UFRGS e da instituição propositora, a FBAUL, o projeto contou com a participação da Michaelis School of Fine Art, da University of Cape Town, África do Sul, e, novamente, da Akademia Sztuk Pieknych, de Lodz, Polônia.
3. Ocorreram exposições simultâneas na Galeria da Faculdade de BelasArtes da Universidade de Lisboa, Portugal, na Academie Galerie, da Faculteit Beeldende Kunst en Vormgeving, em Utrecht, Holanda, na Galeria Kobro, da Akademia Sztuk Pięknych, em Lodzi, Polônia e na Sala de Exposiciones de la Facultad de Bellas Arts de la Universitat de Barcelona, Espanha. 
4. Além de contar com o grande público que regularmente frequenta o CCCEV, teve sua visitação ampliada pela proximidade geográfica com a praça da Alfândega, onde ocorria, naquele momento, a tradicional Feira do Livro de Porto Alegre.

5. Pró-Reitoria de Extensão.

6. Ocorreram exposições na Galeria Kobro, da Akademia Sztuk Pięknych, em Lodz, Polônia, na Torre de Belém, no Goethe Institute na Galeria da Faculdade de BelasArtes da Universidade de Lisboa, em Lisboa, Portugal, no Centre for African Studies Gallery (CAS), da University of Cape Town, na Cidade do Cabo, África do Sul.

7. Por meio de Programas de Fomento da PROREXT e da PROPESQ.

8. The Rape of Europe, 2013 | ISBN 978-989-8300-78-2 | 160 p. Bilíngue - português/inglês e Rhinos are Coming, 2014 / ISBN 978-989-8771-04-9 / 192 p. Bilíngue - português/inglês.

9. Núcleo de Arte Impressa, liderado por Helena Kanaan e composto por acadêmicos do Instituto de Artes UFRGS.

10. Rhinocerus, 2016 / ISBN 9788555490163 / 200 p. Bilíngue português/alemão.

11. Em 2016, foram realizadas as exposições Arte impressa: Entre Gravuras e Rinocerontes, no Museu da Gravura Brasileira, em Bagé, e Entre grabados y rinocerontes: Deambulaciones, no Instituto Cultural Paraguayo-Alemán, em Assunção, Paraguai. Em 2017, foram realizadas as exposições Entre grabados y rinocerontes: Deambulaciones, na Embajada de Brasil, em Buenos Aires, Argentina, e Impressões do Imaginário: 500 anos de Ganda, na Galeria da Escola de Belas Artes da UFMG, em Belo Horizonte, Minas Gerais.
Tendo como referência uma imagem tão celebrada e consolidada em nosso imaginário, resultou uma instigante exposição que incluiu, novamente, gravuras, monotipias, objetos e instalações. Exibida em Porto Alegre, no Centro Cultural CEEE Erico Verissimo (CCCEV), atingiu um público bastante expressivo e entusiasta ${ }^{4}$. Bolsistas PROREXT/UFRGS 5 foram engajados em ações pedagógicas junto ao numeroso público escolar e, de forma semelhante ao projeto The Rape of Europe, ciclos de palestras foram realizados em Porto Alegre e em Lisboa. Conjuntos idênticos de obras foram exibidas nas demais cidades sede das instituições participantes ${ }^{6}$. Desta vez, o protagonismo internacional dos seminários correlatos ficou com o Instituto de Artes da UFRGS que, com apoio da CAPES e da UFRGS ${ }^{7}$, pôde contar com conferencistas convidados de todas as instituições envolvidas, entre eles o artista e professor Stephen Inggs, da Michaelis School of Fine Art, da University of Cape Town, que, além das questões poéticas e míticas implicadas, trouxe a Porto Alegre um impactante depoimento da realidade local deste paquiderme despojado de exotismo para os sul-africanos.

Ambos projetos resultaram em publicações ${ }^{8}$ com reproduções das obras e artigos de pesquisadores das instituições participantes. Após as exposições, as obras de cada conjunto exposto passou a integrar o acervo institucional da escola participante.

\section{O PROJETO RHINOCEROS E AS COLABORAÇÕES COM O GOETHE-INSTITUT PORTO ALEGRE}

O projeto Rhinoceros, realizado em parceria com o Goethe-Institut Porto Alegre, sob a curadoria de Helena Kanaan, deu segmento à celebração dos 500 anos de Ganda, o rinoceronte magistralmente representado em xilogravura por Dürer, que tornou-se uma das imagens mais conhecidas e reproduzidas no mundo ocidental.

A exposição Deambulações: Entre Gravuras e Rinocerontes, foi exibida na Galeria do Goethe-Institut Porto Alegre, em 2015, contando com dezoito obras de artistas do Brasil, da Argentina, da Espanha, dos Estados Unidos e da Alemanha, vinculados a instituições de ensino e fomento da gravura, além de obra conjunta do coletivo $\mathrm{NAI}^{9}$.

Gravuras, impressões digitais, livros de artista, objetos e instalações integraram a mostra que buscou celebrar e refletir sobre permanência da imagem de Ganda sob a ótica da arte impressa hoje. Em paralelo à exposição, foi realizado o seminário Gravura, Palavra, Imaginário: 500 Anos de Ganda, contando com palestras de teóricos e artistas pesquisadores dos cinco países envolvidos.

Posteriormente, o projeto deu origem à belíssima publicação Rhinocerus: Gravura, Palavra, Imaginário ${ }^{10}$, com reprodução das obras e textos dos conferencistas e, por sua vez, a exposição tem realizado uma frutífera itinerância ${ }^{11}$. 
$\mathrm{Na}$ esteira da crescente revalorização do campo da gravura, Marina Ludemann, diretora do Goethe-Institut Porto Alegre, destaca que a exposição Um olhar de Berlim sobre a Arte Impressa em Porto Alegre marcou "o início de um trabalho em rede, uma cooperação internacional duradoura na área da gravura contemporânea".12

Com a curadoria de Rolf Külz-Mackenzie, convidado do Goethe-Institut Porto Alegre, a exposição foi realizada em 2016 no Museu de Arte do Rio Grande do Sul (MARGS) com obras selecionadas do acervo artístico da Pinacoteca Barão de Santo Ângelo, do Instituto de Artes da UFRGS, estreitando os laços de colaboração entre o Goethe-Institut Porto Alegre e o IA/UFRGS.

Mais recentemente, o interesse do Goethe-Institut Porto Alegre pela arte impressa pode ser aferido pelas expressivas ações realizadas no âmbito do projeto The Power of Printmaking ${ }^{13}$ que, entre outras, instituiu o Concurso de Arte Impressa. 0 concurso, já em sua segunda edição, selecionou artistas para exposições na Galeria do Goethe-Institut Porto Alegre, tendo contado com a colaboração de pesquisadores vinculados ao Instituto de Artes da UFRGS.

\section{EXPOSIÇÕES DE NILZA HAERTEL E DE MARIA LUCIA CATTANI}

Em 2016, realizamos duas grandes exposições com obras, sobretudo de gravura, de Nilza Haertel e de Maria Lucia Cattani, ex-docentes do Instituto de Artes da UFRGS.

A mostra Nilza Haertel: Experimentações Gráficas, teve lugar no Centro Cultural CEEE Erico Verissimo, com curadoria de Helena Kanaan e minha. A ideia da exposição impôs-se a nós ao final de 2015, quando a família da artista, falecida em 2014, propôs a doação de seu acervo ao IA/UFRGS.

Considerando-se que, em vida, Nilza Haertel raras vezes exibiu trabalhos, após abrir algumas pastas, ficamos absolutamente surpresas e maravilhadas com a intensidade e sensibilidade de sua produção, na qual se destaca, especialmente, uma profusão de litografias (fig. 1).

Assim, foi com grande alegria que nos incumbimos de apresentar uma primeira leitura deste acervo de grande fôlego, no qual a atitude investigativa da artista se revela. De forma a estabelecer uma reflexão pertinente, organizei o seminário 0 artista pesquisador na universidade, com artistas pesquisadores vinculados a instituições de ensino.
12. Apresentação do catálogo da exposição. Um Olhar de Berlim Sobre uma Arte Impressa em Porto Alegre. Curadoria de Rolf Külz-Mackenzie. Disponível em https://issuu.com/ difusaoddc/docs/catalogo_goethe web Bilíngue - português/inglês, consultado em outubro de 2016.

13. Em 2016, além da exposição Um olhar de Berlim sobre a Arte Impressa em Porto Alegre, o projeto proporcionou a residência artística de Thomas Kilpper, no Vila Flores, em Porto Alegre, e o I Concurso de Arte Impressa do Goethe-Institut Porto Alegre, que selecionou quatro artistas para realização de duas exposições na Galeria do Instituto. Em 2017, promoveu a segunda edição do Concurso de Arte Impressa, dentro dos mesmos moldes, e ainda deve, em parceria com o Goethe-Institut de Bogotá, proporcionar residências artísticas a dois artistas, um brasileiro e um colombiano, e trazer a artista berlinense Hanna Hennenkemper para uma residência artística em Porto Alegre e um workshop em Assunção, Paraguai. Em 2018, é previsto 0 oferecimento de residências artísticas em Berlim para artistas sulamericanos.

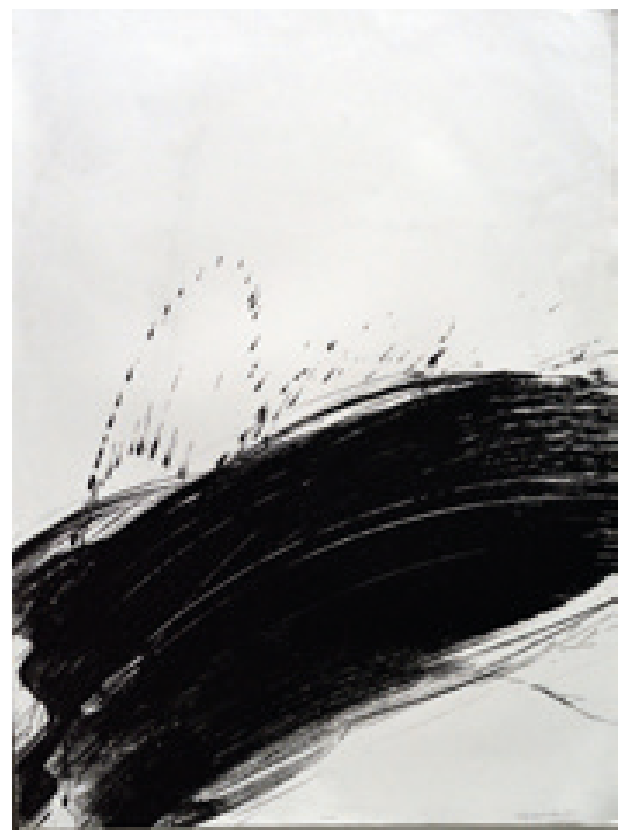

Figura 1. Nilza Haertel. Spring, 1984, litografia, 76,5 x $57 \mathrm{~cm}$. Foto: Maristela Salvatori 
14. Apenas citando muito rapidamente, na obra green 1,600 , por exemplo, um pequeno carimbo de borracha é utilizado para compor 0 grande painel realizado em tinta guache. Existe a matriz, que dá origem às impressões em sequência que, utilizada várias vezes, sem reposição da tinta, origina maculaturas cada vez mais esvanecidas, até a matriz ser novamente entintada e reiniciar este processo cujo resultado e pensamento é gráfico e pictórico.

Figura 2. Vista parcial da exposição de Maria Lucia Cattani: Gestos e Repetições, Pinacoteca Barão de Santo Ângelo, IA/UFRGS, 2017. Foto: Filipe Conde.

Como habitualmente no CCCEV, a mostra atraiu grande público e contou com numerosas visitas de escolas públicas da região metropolitana de Porto Alegre.

A exposição Maria Lucia Cattani: Gestos e Repetições (fig. 2), realizada na Galeria da Pinacoteca Barão de Santo Ângelo, do IA/UFRGS, teve curadoria minha e de Paulo Silveira e constituiu-se como a primeira exposição panorâmica da artista, falecida em 2015. A mostra possibilitou uma revisitação de sua extensa e vigorosa produção poética, de caráter essencialmente múltiplo e perpassada por cruzamentos de linguagem ${ }^{14}$ (fig. 3). Reuniu desenhos, gravuras, pinturas, instalações, objetos e vídeos e apresentou alguns trabalhos inéditos em Porto Alegre.

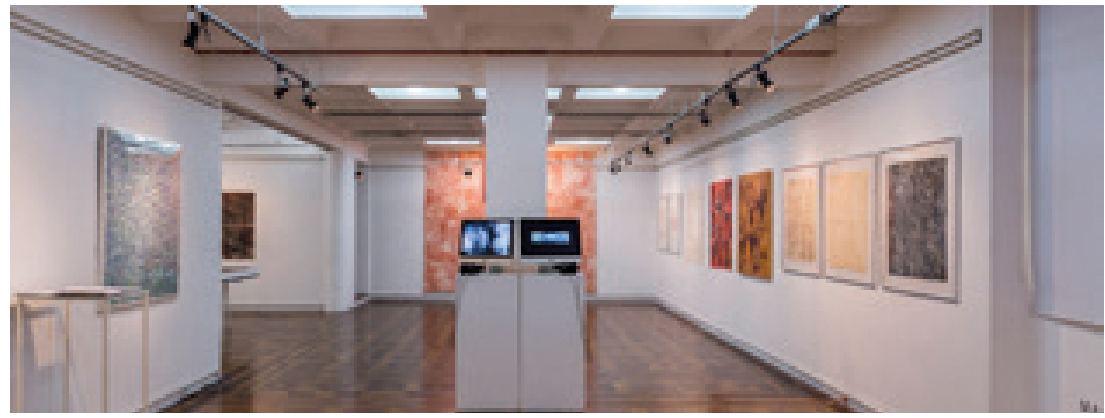

Editou-se uma publicação homônima, e a exposição foi aberta em meio à realização do $25^{\circ}$ Encontro Nacional da Associação Nacional de Pesquisadores em Artes Plásticas (ANPAP), e ao ocorrer na UFRGS, desfrutou de um público especializado adicional.

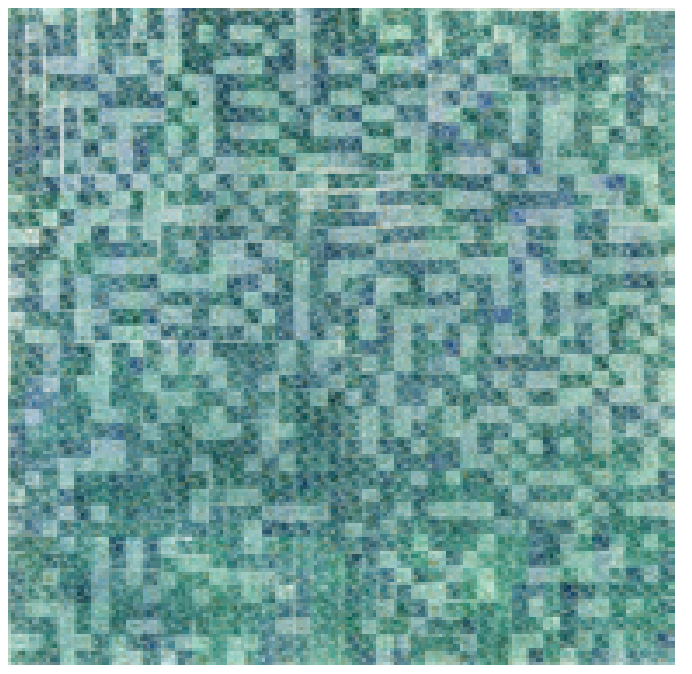

De forma a estabelecer um diálogo com a exposição, organizei o seminário Múltiplos e Únicos com artistas pesquisadores, evento que foi seguido pelo lançamento dos livros A última parede e Vaga-Lume: mostra de vídeo experimental, publicações vinculadas ao seu legado, e encerrado com a Lecture-recital: Scattered Loves de Celso Loureiro Chaves e Um Ponto ao Sul de Maria Lúcia Cattani - intersecções composicionais, nas quais o compositor executou e comentou o processo de criação da peça musical que escreveu a partir de página de livro da artista de Maria Lucia Cattani.

A exposição Maria Lucia Cattani: Gestos e Repetições veio a receber o Troféu Açorianos de Artes

Figura 3. Maria Lucia Cattani, green $1,600,1998$, guache sobre papel, 124 x $124 \mathrm{~cm}$. Foto: Maristela Salvatori
Plásticas, na categoria Destaque em Acervo e Memória, da Prefeitura Municipal de Porto Alegre, em sua décima edição (2016). 


\section{PRODUÇÕES POÉTICAS DO GRUPO DE PESQUISA}

Ainda em 2016, com a presença do professor Bernard Paquet (Université Laval, Québec, Canadá), em estágio Pós-Doutoral em Porto Alegre, reunimos o grupo de pesquisa e concebemos, com curadoria minha e dele, a exposição Expressões do Múltiplo (fig. 4), visando apresentar resultados de pesquisas recentes de integrantes do grupo, aos quais se juntaram obras de dois outros convidados. Em paralelo, organizei o seminário Expressões do Múltiplo: Interfaces, enfocando experiências contemporâneas em torno do múltiplo sob diferentes óticas, com a participação de Bernard Paquet e pesquisadores convidados.

O seminário foi pensado para ocorrer dentro do período da exposição, porém, face à ocupação do IA/UFRGS por estudantes, que restringiu o acesso à Pinacoteca do IA/ UFRGS, local planejado para ambos eventos, e à iminente partida do Brasil do colaborador canadense, optamos por realizá-lo na Mamute Galeria de Arte, e a exposição foi deslocada para 2017, com a retomada das atividades institucionais.

A exposição espelhou o foco do grupo, que se dedica a investigações sobre processos e a experimentações poéticas em gravura, vídeo, fotografia, entre outras possibilidades do múltiplo, considerando cruzamentos e contaminações de meios. Abarcando produções bastante diferenciadas, a exposição buscou estabelecer uma conversa entre as pesquisas do grupo, sem fechar conceitos, pois, tal como aponta Stephen Bury, enquanto artistas estiverem conscientemente subvertendo ou expandindo imagens, materiais e métodos de outros criadores, qualquer definição de múltiplo será difícil (2001, p.37).

Bernard Paquet desenvolve um trabalho em pintura no qual a serialidade e a repetição são preponderantes, seja na recorrência a formas semelhantes, que se desdobram incessantemente, seja no próprio gesto pictórico de sobrepor camadas. ${ }^{15} \mathrm{Na}$ exposição, mostrou representações de um mundo reinventado e povoado por seres humanos sem gênero ${ }^{16}$ e experimentou novas interfaces ao apresentar virtualmente suas pinturas em projeções sobre a parede.

Com uma abordagem bem diferenciada, Roseli Nery também recria mundos. Suas Colônias são constituídas por diminutos objetos industrializados. Comumente do universo feminino, e encontrados em armarinhos, estes objetos, que em seus empregos usuais geralmente passam despercebidos, aqui adquirem uma singularidade forjada pelo arranjo e acúmulo.

15. Seus DNAs, como Bernard Paquet nomeia as pequenas obras que acompanham as telas, e que fazem às vezes de etiquetas ou códigos de barra, são realizados com tinta acrílica exaustivamente acrescida em camadas sobre meio acrílico (transparente) que, depois de cortadas em tiras, são rearranjadas e novamente cobertas por camadas de meio acrílico. Um trabalho extremamente demorado e meticuloso.

16. Ver artigo de Bernard Paquet, nesta edição. 
17. Artista que também participa desta edição com uma resenha.

18. Junto aos balões disponibilizados ao público que continham a inscrição, em serigrafia, "Espaço de Conflito"-, encontravam-se as instruções: Para encher balões, sente-se e observe o espaço ao seu redor. Inspire e solte 0 ar comprimido de seu peito, enchendo 0 balão. Amarre-0 e solte-o no espaço expositivo. Você é convidado(a) a encher 0 máximo de balões que conseguir.

Jander Rama ${ }^{17}$, assim como Bernard Paquet, projetou imagens de futuro, utilizando, em gravura, a linguagem de manuais técnicos, criando ciborgues que misturam fantasia, obsolescência e muita ironia.

Alice Porto apresentou na mostra impressões digitais da série Marcha dos vadios, na qual reelabora imagens coletadas em redes sociais, trazendo à tona questões de gênero. Focando questões semelhantes, Natasha Kulczynski utiliza fotografias e vídeo e incarna personas, nestas, sua cabeça raspada - despida do cabelo, forte símbolo indenitário feminino -, é ofertada para interferências.

Na performance de Carla Borba, encontramos quase um apelo a manter o equilíbrio pela respiração. Em Espaço de conflito, que evoca o frágil momento vivido no Brasil, a artista insufla balões coloridos e convida o público a fazer o mesmo ${ }^{18}$. Os balões enchidos são deixados na galeria e, progressivamente, a ocupam deixando os traços da performance, resultando uma instalação em constante mobilidade (fig. 4).

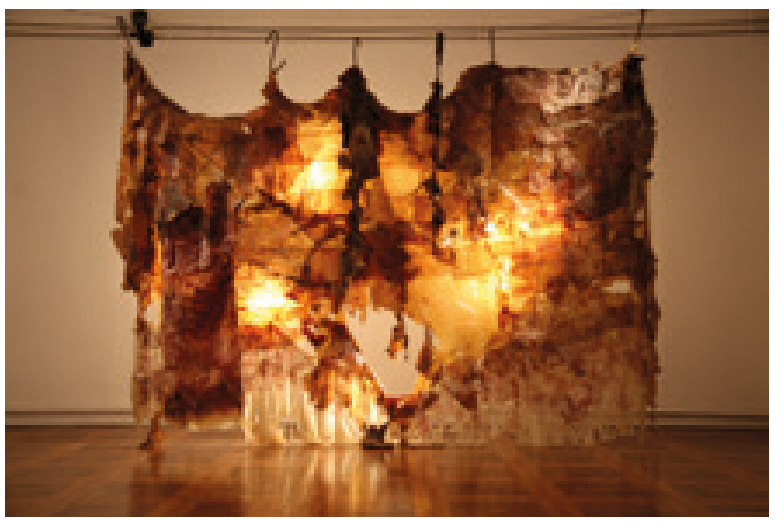

Helena Kanaan que, por ocasião do seminário, também lançou o livro Impressões, Acúmulos e Rasgos (2016), apresentou trabalho homônimo (fig. 5), uma instalação com aguadas litográficas e látex, que compreendia um painel suspendido por ganchos de açougue e um objeto vestível. As texturas e cores do látex, que já remetiam à pele humana, com o emprego dos ganchos que estiravam os volumes, ganhou força e contundência. Coincidentemente à abertura da exposição, foi deflagrada a Operação Carne Fraca ${ }^{19}$, da Polícia

Figura 5. Helena Kanaan, Impressões, acúmulos e rasgos, 2011/16, instalação com aguada litográfica e látex, $180 \times 300 \mathrm{~cm}$. Exposição Expressões do Múltiplo. Pinacoteca Barão de Santo Ângelo, IA/UFRGS, 2017. Foto: Giordana Winkcler.

19. Mais um dos recentes $e$ sucessivos escândalos da corrupção no Brasil, este envolvendo 0 comércio de carne. Ver https:/ www.cartacapital.com.br/politica/ operacao-carne-fraca-e-fragil-masuma-coisa-e-certa-ha-corrupcao. 20. Artista que também participa deste dossiê com uma resenha. 21. Artista convidada que também participa deste dossiê com um artigo. 22. Artista convidada que, atualmente, é integrante do grupo de pesquisa.
Federal brasileira, tornando-se inevitável sua reverberação na leitura do trabalho.

Os registros fotográficos e subprodutos de performances de Janete Fonseca, como os relevos em transparências, traziam a impressão de peles marcadas, vestígios de cicatrizes. As transparências, formadas por cola branca, sofriam a ação da água acrescida, que as remodelava.

Imagens fotográficas, ou com um léxico mais fotográfico, foram também trazidas por Flavya Mutran ${ }^{20}$, por Lurdi Blauth ${ }^{21}$, por Márcia Sousa ${ }^{22}$ e por mim. As fotografias de Flavya Mutran apresentavam sobreposições que deixavam traços, como pentimentos e/ou palimpsestos, e construíam narrativas. Nas fotografias de Márcia Sousa, as plantas invadem construções em processo de deterioração, gerando nova vida, criando poesia visual.

No meu trabalho, transitei entre linguagens, configurando paisagens urbanas em painéis compostos por fragmentos justapostos de fotografias e de monotipias. Um segundo cenário foi constituído pela maculatura do primeiro, como imagens em desaparição. Já em Travessias Rio Negro, Lurdi Blauth 
utilizou recursos de transposição da imagem fotográfica para a matriz de metal que, posteriormente, foi retrabalhada com técnicas tradicionais sem perder seus aspectos indiciários e, desta forma, fundindo estas linguagens.

Certamente, é difícil circunscrever tanto o que seja o múltiplo, quanto a gravura hoje. Christophe Cherix destaca, por ocasião da curadoria da exposição Print/Out (MoMa, 2012), a natureza versátil e, por vezes, mesmo confusa, da arte contemporânea nas últimas décadas. Fronteiras geopolíticas mudaram e novas tecnologias forjaram canais de comunicação ao redor do mundo, onde materiais impressos têm desempenhado um importante papel (2012, p.15).

Iniciativas e projetos aqui apresentados sinalizam práticas artísticas relacionadas ao múltiplo e à mídia impressa, que corroboram com a ideia da apropriação de novas tecnologias, assim como a revisitação de velhas tecnologias na produção poética contemporânea. Sem preconceitos, diferentes recursos são utilizados, isoladamente ou em associação. Sobrepõem-se processos e linguagens, expandem-se conceitos e fronteiras. 


\section{REFERÊNCIAS}

BURY, S. Artists' Multiples. 1935-2000. Aldershot: Ashgate, 2001.

CHERIX, Christophe et. al. Print/Out: 20 Years in Print. NY:

Museum of Modern Art, 2012.

COLDWELL, Paul. Printmaking: A Contemporary Perspective. London: Back Dog, 2010.

KANAAN, H; SALVATORI, M. Das Marcas de um Rhinoceros: Vertentes da arte impressa hoje. In: $A$ arte: seus espaços e/ em nosso tempo. $25^{\circ}$ Encontro Nacional de Pesquisadores em Artes Plásticas da ANPAP. Porto Alegre: ANPAP/ PPGAV/UFRGS, 2016. p.1642-1656. Disponível em: http:// anpap.org.br/anais/2016/ acessado em dezembro de 2016. KANAAN, H. (org.) Rhinocerus. Porto Alegre: Libretos, 2016. KÜLZ-MACKENZIE, Rolf. Um Olhar de Berlim Sobre uma Arte Impressa em Porto Alegre. Catálogo da exposição Porto Alegre: MARGS, 2016. Disponível em: https://issuu.com/ difusaoddc/docs/catalogo_goethe_web acessado em outubro de 2015.

QUARESMA, J. (org.) Rhinos are Coming. Lisboa: FBAUL, 2014.

QUARESMA, J. (org.) The Rape of Europe. Lisboa: FBAUL, 2013. Disponível em: https://issuu.com/fbaul/docs/rapto_da_ europa/157 acessado em agosto de 2015.

SALVATORI, M; SILVEIRA, P. Maria Lucia Cattani: Gestos e repetições. Porto Alegre: Marca Visual, 2016.

SALVATORI, Maristela. Compartilhamentos em gravura: 0 Instituto de Artes da UFRGS no projeto Rhinos are coming In: Compartilhamentos na Arte: Redes e Conexões. Anais do $24^{\circ}$ Encontro Nacional de Pesquisadores em Artes Plásticas da ANPAP. Santa Maria: ANPAP/PPGART/CAL/ UFSM, 2015. p.2690-2704. Disponível em: http://anpap.org. br/anais/2015/ acessado em agosto de 2016.
SAUNDERS, Gill; MILES, Rosie. Prints Now: Directions And Definitions, London: Victoria \& Albert, 2006.

VENEROSO, Maria do Carmo. 0 campo ampliado da gravura. In: Art Research Journal. Vol. 1/1 | p.171-183| Jan./Jun. 2014. Disponível em: https://periodicos.ufrn.br/artresearchjournal/ article/view/5275Capturado acessado em agosto de 2016.

\section{Maristela Salvatori}

Artista Visual. Docente do Instituto de Artes - UFRGS, onde foi Coordenadora do Programa de Pós-Graduação em Artes Visuais. Doutora em Artes e Ciências das Artes por Paris I, Estágio Sênior/CAPES, na Université Laval, Canadá. Artista Residente na Cité Internationale des Arts, Paris, e no Centro Frans Masereel, Kasterlee. Membro da ANPAP e do Conselho Editorial das Revistas :Estúdio, Gama e Cromo, da FBAUL. Líder do Grupo de Pesquisa Expressões do Múltiplo CNPq-PPGAV/ IA/UFRGS. Bolsista de Produtividade em Pesquisa do CNPq.

(*) Artigo enviado em agosto de 2017. 